\title{
Impact of multi-disciplinary treatment strategy on systolic heart failure outcome
}

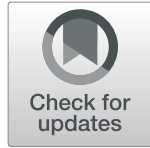

\author{
Shyh-Ming Chen ${ }^{1,2^{*}+} \mathbb{D}$, Yen-Nan Fang ${ }^{1,2+}$, Lin-Yi Wang ${ }^{3,2}$, Ming-Kung Wu ${ }^{4,2}$, Po-Jui Wu ${ }^{1,2}$, Tsung-Hsun Yang ${ }^{3,2}$, \\ Yung-Lung Chen ${ }^{1,2}$ and Chi-Ling Hang ${ }^{1,2}$
}

\begin{abstract}
Background: Patients with reduced ejection fraction have high rates of mortality and readmission after hospitalization for heart failure. In Taiwan, heart failure disease management programs (HFDMPs) have proven effective for reducing readmissions for decompensated heart failure or other cardiovascular causes by up to $30 \%$. However, the benefits of HFDMP in different populations of heart failure patients is unknown.
\end{abstract}

Method: This observational cohort study compared mortality and readmission in heart failure patients who participated in an HFDMP (HFDMP group) and heart failure patients who received standard care (non-HFDMP group) over a 1-year follow-up period after discharge (December 2014 retrospectively registered). The components of the intervention program included a patient education program delivered by the lead nurse of the HFDMP; a cardiac rehabilitation program provided by a physical therapist; consultation with a dietician, and consultation and assessment by a psychologist. The patients were followed up for at least 1 year after discharge or until death. Patient characteristics and clinical demographic data were compared between the two groups. Cox proportional hazards regression analysis was performed to calculate hazard ratios (HRs) for death or recurrent events of hospitalization in the HFDMP group in comparison with the non-HFDMP group while controlling for covariates.

Results: The two groups did not significantly differ in demographic characteristics. The risk of readmission was lower in the HFDMP group, but the difference was not statistically significant $(H R=0.36, p=0.09)$. In patients with ischemic cardiomyopathy, the risk of readmission was significantly lower in the HFDMP group compared to the non-HFDMP group ( $H R=0.13, p=0.026)$. The total mortality rate did not have significant difference between this two groups.

Conclusion: The HFDMP may be beneficial for reducing recurrent events of heart failure hospitalization, especially in patients with ischemic cardiomyopathy.

Trial registration: Longitudinal case-control study ISRCTN98483065, 24/09/2019, retrospectively registered.

Keywords: Heart failure, Disease management program, Readmission, Cardiac rehabilitation

\footnotetext{
* Correspondence: syming99@gmail.com

'Shyh-Ming Chen and Yen-Nan Fang are co-first authors in this work

'Section of Cardiology, Department of Internal Medicine, Kaohsiung Chang

Gung Memorial Hospital and Chang Gung University College of Medicine,

123 Tai Pei Road, Niao Sung District, Kaohsiung City 83301, Taiwan, Republic

of China

${ }^{2}$ Heart Failure Center, Kaohsiung Chang Gung Memorial Hospital, 123 Tai Pei

Road, Niao Sung District, Kaohsiung City 83301, Taiwan, Republic of China

Full list of author information is available at the end of the article
}

(c) The Author(s). 2019 Open Access This article is distributed under the terms of the Creative Commons Attribution 4.0 International License (http://creativecommons.org/licenses/by/4.0/), which permits unrestricted use, distribution, and

reproduction in any medium, provided you give appropriate credit to the original author(s) and the source, provide a link to the Creative Commons license, and indicate if changes were made. The Creative Commons Public Domain Dedication waiver (http://creativecommons.org/publicdomain/zero/1.0/) applies to the data made available in this article, unless otherwise stated. 


\section{Background}

Heart failure (HF) is a growing epidemic worldwide, owing to the aging populations and the increasing survival of patients presenting with acute myocardial infarction and various other heart diseases [1]. The HF readmission rate and mortality rate are high in Taiwan. Taiwan Society of Cardiology-Heart Failure with reduced Ejection Fraction (TSOC-HFrEF) registry data reveal an HF readmission rate of $38.5 \%$ and an HF total mortality rate of $15.9 \%$ in 1 year after the index hospitalization [2]. During the 1-year period after index hospitalization, more than half (53.6\%) of HF patients die, are hospitalized for HF, or require left a ventricular assistive device or heart transplantation [2]. Therefore, improvements in HF care in Taiwan are urgently needed. In Taiwan, the heart failure disease management programs (HFDMPs) led by cardiovascular nursing specialists have proven effective for decreasing adverse outcomes of HF and have achieved HF treatment cost savings of up to $41.8 \%$ [3]. These programs can decrease the rate of readmission for HF or other cardiovascular causes by up to $30 \%$ and have a trend toward lower mortality rate by a systemic meta-analysis [4]. According to recently published guidelines, a multidisciplinary team should provide for HF patients with class I level A evidence [5]. Despite convincing evidence of its effectiveness, however, HFDMPs are not been widely used in Taiwan. One reason is that the best design and implementation of an HFDMP is unclear. Additionally, some HFDMPs show not improvements in health status compared with standard care [6, 7]. Another question is whether HFDMP should be provided to all HF patients or only specific subsets.

Therefore, the objective of this study was to design a multi-disciplinary, multi-faceted HFDMP and to compare it with standard care in a population of HF patients with multiple co-morbidities. Patients hospitalized for HF with left ventricular ejection fraction (LVEF) $<40 \%$ were enrolled and studied over a 1-year follow-up period.

\section{Method}

\section{Study design}

This observational cohort study compared rates of mortality and cardiovascular readmission between an HFDMP group and a non-HFDMP group. The subjects included 159 patients admitted for systolic heart failure (LVEF $<40 \%$ ) at a single medical center in south Taiwan from July, 2013 to December, 2014. Of these, 64 consecutive patients were enrolled in a non-HFDMP group that received standard care from July, 2013 to June, 2014, and 95 consecutive patients were enrolled in an HFDMP group that received the HFDMP intervention from May to December, 2014. The inclusion criteria were $\mathrm{HF}$ with reduced $\mathrm{EF}(\mathrm{EF}<40 \%)$, radiographic evidence of pulmonary congestion or typical symptoms and signs of HF, age $>18$ years, and NYHA functional class II-IV. The exclusion criteria were severe respiratory failure under ventilator support, dementia, expectation of short survival, discharge to a geriatric clinic or home care, or current follow-up treatment at the nurse-led HF clinic.

The HFDMP comprised patient education delivered by the lead nurse, dietary consultation, psychological consultation and assessment, and a cardiac rehabilitation program provided by a physical therapist. The patients were followed up for at least 1 year or until death. The outcome measures were readmissions related to cardiovascular problems and all-cause mortality. Clinical demographic data, laboratory findings, and medications were used for risk adjustment.

\section{Intervention protocol}

The education program included the following components:

- Explanation of HF and its causes

- Differences between expected and severe symptoms and how to monitor them

- Symptoms that often occur before HF hospitalization, i.e., dyspnea, edema, fatigue, cough, chest pain, sudden weight gain, difficulty breathing while sleeping, palpitations

- Purpose of each medication and strategies for maintaining compliance with the prescribed dosage

- Importance of risk factor modification

- Individualized recommendations for dietary restrictions on sodium, fluid, and alcohol

- Importance of recording body weight and any changes from a daily basis

- Recommendations for exercise and rest

- Recommended behavioral changes

- How to cope with the disease (psychosocial care)

Patients are also taught the following skills

- Recognition of symptoms

- Important signs and symptoms

- Timely response to symptoms

- When to call the health care provider

- How to differentiate between high- and low-sodium foods

The cardiovascular lead nurse contacted the patient by telephone within 3 days after discharge. An appointment at the outpatient clinic was arranged within 1 to 2 weeks after discharge. The purposes of the telephone call were 
to reinforce self-management and recognition of $\mathrm{HF}$ symptoms and to screen post-discharge health status.

The lead nurse arranged further consultations as needed with the pharmacist, dietician, educator, and psychologist. The patient was encouraged to contact the nurse directly if any questions or problems arose. All patients in the intervention group received phase I cardiac rehabilitation before discharge, and some also received phase II cardiac rehabilitation.

Management and follow up of patients in the control group were performed by the participating physicians according to current clinical practices. No standard format or guidelines were established for the education program provided by the nurse or for the consultations provided by the dietitian and psychologist. Patients in non-HFDMP group did not have cardiac rehabilitation program as patients in HFDMP did.

\section{Statistical analyses}

The $x^{2}$ and $t$ test were used to compare patient characteristics between the HFDMP and non-HFDMP groups. Since a hospital readmission for HF is a recurrent event, Cox proportional hazards regression analysis of recurrent events was performed using the Wei, Lin, and Weissfeld (1989) method based on marginal Cox models [8] to compare the hazard ratio (HR) of death or readmission between the HFDMP group and the nonHFDMP group while controlling for covariates. The interaction term under the previous model of recurrent events was also used to investigate whether ischemic cardiomyopathy differed between the two groups. This study was approved by the Human Investigation Committee of the Institutional Review Board of Chang-Gung Memorial Hospital in Kaohsiung, Taiwan.

\section{Results}

Demographic and clinical characteristics of 159 heart failure patients are summarized in Table 1. The HFDMP and non-HFDMP groups did not significantly differ in age, gender, cardiovascular function, 1-year mortality, comorbidities, medications, or cardiac resynchronization therapy. However, the use of implantable cardioverter defibrillator (ICD) was significantly higher in the HFDMP group (12.63\%) compared to the non-HFDMP group (1.56\%). Covariate-adjusted analysis revealed that HF readmissions and mortality were lower in the HFDMP group. However, the difference in HF readmissions between the HFDMP group (29.67\%) and the nonHFDMP group (30.51\%) did not reach statistical significance $(p=0.91)$ (Table 2). Additionally, the difference in 1-year mortality between the HFDMP group $(11.58 \%)$ and the non-HFDMP group (17.19\%) did not reach statistical significance $(p=0.32)$. All patients in the HFDMP had received phase I cardiac rehabilitation. However,
Table 1 Demographic and clinical characteristics of $159 \mathrm{HF}$ patients

\begin{tabular}{|c|c|c|c|c|c|c|}
\hline \multirow[t]{2}{*}{ Variables } & \multicolumn{2}{|l|}{ HFDMP } & \multicolumn{2}{|c|}{ non-HFDMP } & \multirow[t]{2}{*}{$x^{2} / t$} & \multirow[t]{2}{*}{$p$} \\
\hline & $\mathrm{n} /$ means & $\% / s t d$. & $\mathrm{n} /$ means & $\% / s t d$. & & \\
\hline Age & 69.79 & 14.98 & 70.47 & 14.01 & -0.29 & .77 \\
\hline Gender & & & & & 1.63 & .20 \\
\hline Male & 59 & 62.11 & 46 & 71.88 & & \\
\hline Female & 36 & 37.89 & 18 & 28.13 & & \\
\hline peak $\mathrm{VO}_{2}$ & 14.07 & 3.32 & 17.50 & 2.12 & -1.40 & .18 \\
\hline VENCO ${ }_{2}$ at AT & 39.92 & 6.46 & 33.00 & 0.00 & 1.47 & .17 \\
\hline Mortality & & & & & 1.01 & .32 \\
\hline Survival & 84 & 88.42 & 53 & 82.81 & & \\
\hline Death & 11 & 11.58 & 11 & 17.19 & & \\
\hline LVEF & 32.25 & 5.87 & 31.03 & 7.16 & 1.18 & .24 \\
\hline Atrial Fibrillation & & & & & $0.95^{\mathrm{a}}$ & .81 \\
\hline non AF & 59 & 62.11 & 44 & 68.75 & & \\
\hline Paroxysmal AF & 24 & 25.26 & 14 & 21.88 & & \\
\hline Persistent AF & 3 & 3.16 & 1 & 1.56 & & \\
\hline Permanent AF & 9 & 9.47 & 5 & 7.81 & & \\
\hline Ischemic CM & 56 & 58.95 & 36 & 56.25 & 0.11 & .74 \\
\hline Hypertension & 74 & 77.89 & 50 & 78.13 & 0.00 & .97 \\
\hline Diabetes mellitus & 44 & 46.32 & 24 & 37.50 & 1.21 & .27 \\
\hline Hyperlipidemia & 56 & 58.95 & 30 & 46.88 & 2.24 & .13 \\
\hline Stroke & 23 & 24.21 & 13 & 20.31 & 0.33 & .56 \\
\hline Old Ml & 31 & 32.63 & 23 & 35.94 & 0.19 & .67 \\
\hline PAD & 16 & 16.84 & 8 & 12.50 & 0.56 & .45 \\
\hline CKD & 59 & 62.11 & 44 & 68.75 & 0.74 & .39 \\
\hline $\mathrm{PCl}$ & 36 & 37.89 & 23 & 35.94 & 0.06 & .80 \\
\hline \multicolumn{7}{|c|}{ Medication / Treatment } \\
\hline ACEI/ARB & 76 & 80.00 & 49 & 76.56 & 0.27 & .60 \\
\hline$\beta$-blocker & 62 & 65.26 & 40 & 62.50 & 0.13 & .72 \\
\hline Aldactone & 38 & 40.00 & 19 & 29.69 & 1.77 & .18 \\
\hline Diuretics & 74 & 77.89 & 48 & 75.00 & 0.18 & .67 \\
\hline Digoxin & 17 & 17.89 & 5 & 7.81 & 3.26 & .07 \\
\hline$I C D$ & 12 & 12.63 & 1 & 1.56 & 6.24 & .01 \\
\hline CRT & 7 & 7.37 & 4 & 6.25 & $0.07^{\mathrm{a}}$ & 1.00 \\
\hline
\end{tabular}

Abbreviations: HFDMP heart failure disease management program, VE minute ventilation, $A T$ anaerobic threshold, $L V E F$ left ventricular ejection fraction, $A F$ atrial fibrillation, $C M$ cardiomyopathy, $H F$ heart failure, $M I$ myocardial infarction, $P A D$ peripheral artery disease, $C K D$ chronic kidney disease, $P C l$ percutaneous coronary intervention, $A C E I$ angiotensin converted enzyme inhibitor, $A R B$ angiotensin receptor blocker, ICD implantable cardioverter defibrillator, $C R T$ cardiac resynchronization therapy

${ }^{\mathrm{a}}$ Fisher exact test

only 15 patients $(15.8 \%)$ in the HFDMP group had received phase II cardiac rehabilitation. No patients in the non-HFDMP group had received cardiac rehabilitation.

Table 3 shows the Cox proportional hazard model results for recurrent events of cardiovascular hospitalization in the HF patients. Readmission risk was lower in the HFDMP 
Table 2 Outcomes analysis

\begin{tabular}{llll}
\hline Variable & $\begin{array}{l}\text { HFDMP } \\
(n=95)\end{array}$ & $\begin{array}{l}\text { non-HFDMP } \\
(n=64)\end{array}$ & $P$-value \\
\hline Readmission within 30 days (\%) & 4.30 & 3.28 & 1.00 \\
Readmission within 6 months (\%) & 20.88 & 21.67 & 0.91 \\
Readmission within 1 year (\%) & 29.67 & 30.51 & 0.91 \\
Death within 30 days (\%) & 3.16 & 6.25 & 0.44 \\
Death within 6 months (\%) & 10.53 & 12.50 & 0.70 \\
Death within 1 year (\%) & 11.58 & 17.19 & 0.32 \\
\hline
\end{tabular}

Abbreviations: HFDMP heart failure disease management program, Non-HFDMP standard care

group compared to the non-HFDMP group (HR $=0.36$, 95\% confidence interval $[\mathrm{CI}] 0.11-1.19, p=0.09)$, but the difference did not reach statistical significance. The interacting terms in the previous Cox model of recurrence were further used to compare different subgroups of patients who had received HFDMP. Figure 1 shows that ischemic cardiomyopathy patients had a lower readmission risk compared to non-ischemic cardiomyopathy under HFDMP $(\mathrm{HR}=0.13,95 \%$ CI 0.02-0.79, $p=0.03)$.

\section{Discussion}

This observational cohort study revealed that HFDMP did not significantly reduce 1 -year cardiovascular readmissions in HFrEF patients. However, the Cox model of recurrent events showed that ischemic cardiomyopathy patients had a significantly lower risk of readmission compared to all other subgroups of HFrEF patients. $(\mathrm{HR}=0.13,95 \%$ CI $0.02-0.79, p=0.03)$. Disease management interventions for HF are highly heterogenous and complex and often yield mixed results in different HF populations [9-17]. Our intervention program was led by a cardiovascular nursing specialist and an HF cardiologist. The program also included cardiac rehabilitation and psychiatric interventions. Notably, progressive enlargement, dilatation, and global or regional dysfunction of the left ventricle can result from secondary myocardial damage in HF patients with ischemic cardiomyopathy $[18,19]$. Myocardial remodeling may precede deterioration of exercise capacity and HF hospitalization in these patients [20]. Our disease management program included cardiac rehabilitation, which can reportedly improve cardiopulmonary function and reduce recurrent events of hospitalization in HF patients with ischemic cardiomyopathy [21].

Researchers and policy makers have shown great interest in the concept of preventing readmissions in HF patients. The 30-day readmission rate, which is an important measure of hospital performance, has been linked to financial penalties in the USA [22]. Additionally, 30-day readmission is associated with poor prognosis at 6-month follow up [23]. An analysis of 43,143 patients treated at
Table 3 Results of Cox model of recurrent events of hospitalization in HF patients

\begin{tabular}{|c|c|c|c|c|c|}
\hline Variables & $\beta$ & S.E. & $H R$ & HR 95\% Cl & $p$ \\
\hline \multicolumn{6}{|l|}{ Group } \\
\hline non-HFDMP & ref. & & 1.00 & & \\
\hline HFDMP & -1.03 & 0.62 & 0.36 & $0.11-1.19$ & .09 \\
\hline Age & 0.03 & 0.02 & 1.03 & $0.99-1.06$ & .14 \\
\hline \multicolumn{6}{|l|}{ Gender } \\
\hline Female & ref. & & 1.00 & & \\
\hline Male & 0.23 & 0.29 & 1.26 & $0.71-2.22$ & .43 \\
\hline Ischemic CM & -0.32 & 0.46 & 0.72 & $0.29-1.78$ & .48 \\
\hline Hypertension & -0.42 & 0.48 & 0.65 & $0.25-1.68$ & .38 \\
\hline Diabetes mellitus & -0.55 & 0.38 & 0.58 & $0.28-1.21$ & .14 \\
\hline Hyperlipidemia & 0.00 & 0.68 & 1.00 & $0.27-3.77$ & 1.00 \\
\hline Stroke & 0.78 & 0.56 & 2.18 & $0.72-6.54$ & .17 \\
\hline Old Ml & 0.10 & 0.59 & 1.11 & $0.35-3.51$ & .87 \\
\hline PAD & 0.51 & 0.52 & 1.67 & $0.60-4.67$ & .33 \\
\hline CKD & -0.78 & 0.52 & 0.46 & $0.17-1.26$ & .13 \\
\hline \multicolumn{6}{|l|}{ Atrial Fibrillation } \\
\hline Without AF & ref. & & 1.00 & & \\
\hline Paroxysmal & -0.30 & 0.61 & 0.74 & $0.22-2.47$ & .63 \\
\hline Persistent & -2.06 & 1.05 & 0.13 & $0.02-1.01$ & .05 \\
\hline Permanent & -0.32 & 0.79 & 0.73 & $0.15-3.42$ & .69 \\
\hline $\mathrm{PCl}$ & 0.44 & 0.64 & 1.55 & $0.44-5.39$ & .49 \\
\hline LVEF & 0.01 & 0.03 & 1.01 & $0.96-1.06$ & .73 \\
\hline \multicolumn{6}{|l|}{ Medication } \\
\hline ACEI/ARB & 0.13 & 0.58 & 1.14 & $0.37-3.54$ & .82 \\
\hline$\beta$-blocker & -1.70 & 0.44 & 0.18 & $0.08-0.43$ & $<.01$ \\
\hline Aldactone & 0.98 & 0.54 & 2.68 & $0.93-7.68$ & .07 \\
\hline Diuretics & -0.79 & 0.54 & 0.45 & $0.16-1.29$ & .14 \\
\hline Digoxin & 0.22 & 0.47 & 1.25 & $0.50-3.10$ & .64 \\
\hline ICD & 0.96 & 0.61 & 2.60 & $0.78-8.63$ & .12 \\
\hline CRT & -1.15 & 1.37 & 0.32 & $0.02-4.65$ & \\
\hline
\end{tabular}

Abbreviations: HFDMP heart failure disease management program, $C M$ cardiomyopathy, $H F$ heart failure, $M I$ myocardial infarction, $P A D$ peripheral artery disease, $C K D$ chronic kidney disease, $A F$ atrial fibrillation, $P C I$

percutaneous coronary intervention, LVEF left ventricular ejection fraction, ACEI angiotensin converted enzyme inhibitor, $A R B$ angiotensin receptor blocker, $I C D$ implantable cardioverter defibrillator, CRT cardiac resynchronization therapy, $H R$ Hazard ratio, $\mathrm{Cl}$ confidence interval

171 centers revealed that the hospitals with high riskadjusted 30-day readmission rate also had higher 1-year all cause readmission rate $(59.1 \%$ vs. $54.7 \%$, respectively; $p=0.01$ ) [24]. The HFDMP group in our study had a lower 1-year readmission rate $(29.67 \%)$ compared to HF patients treated with standard care as reported in the TSOC-HFrEF registry (38.5\%) [2] and in HF registries in other countries (e.g., 30.1\% in IN-HF outcome registry in India [25] and 36\% in registry in Saudi Arabia [26]). In comparison, the EHFS-2 registry in Europe reveals a 1- 


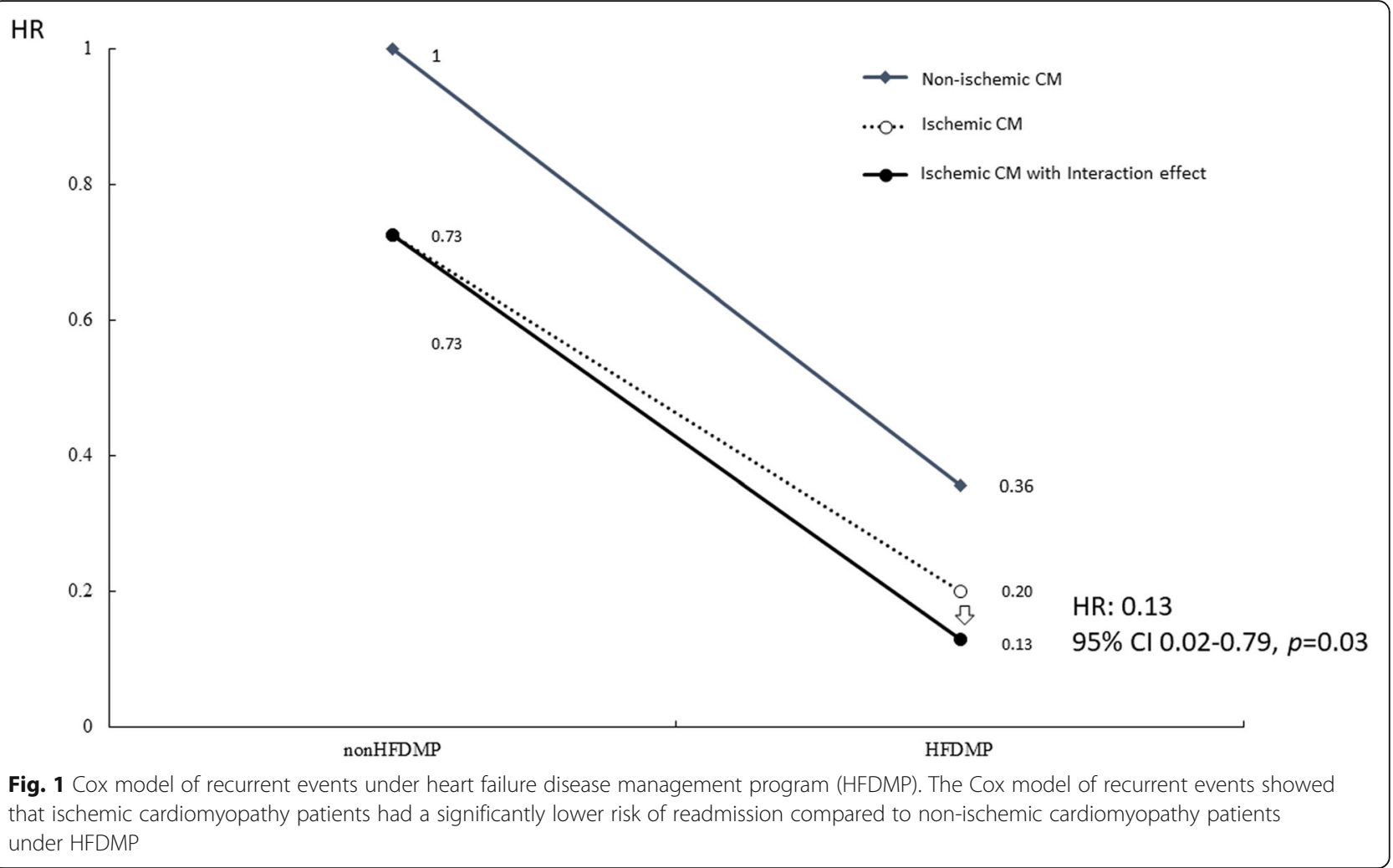

year morality rate of $21.9 \%$ for patients hospitalized with acute HF [27], and the IN-HF registry in India reveals a 1year morality rate of $24.4 \%$ [25]. In a population-based cohort study from the United Kingdom 2000-2017, the overall one-year mortality decreased by $6.6 \%$ for people with a new diagnosis of heart failure from $25.8 \%$ in 2000 to $19.2 \%$ in 2016 [28]. In Asia, 1-year HF mortality rates are 8.9, 9.2 and $19.5 \%$ according to registry data for Japan (JCARE-CARD), Korea (KorHF), and Hong Kong (HongKong HF), respectively. In comparison, the HFDMP group in our study had a 1-year mortality rate of $11.58 \%$.

The HF nursing specialist has a key role as a case manager or coordinator of the HFDMP [29]. A competent HF nursing specialist is essential for providing the education and psychosocial interventions needed to improve drug compliance [30]. A large retrospective cohort study reported that noncompliance with drug therapy is associated with an increased risk of all-cause mortality and cardiovascular hospitalization [31]. In Taiwan, a descriptive, cross-sectional study revealed low self-care maintenance and management in HF patients [32]. A study of a Chinese HF patients further showed that an HFDMP led by a HF nursing specialist can reduce cardiovascular hospitalization and can substantially reduce hospital costs [33]. The results of our study are consistent with previous studies of HFDMPs that included additional components such as cardiac rehabilitation and psychosocial surveillance.
The aims of this study were focused on adverse outcomes. Therefore, we don't have cost analysis for this study. We agree it's an important issue for HFDM program and the results will provide helpful information for policy decision marker. In the believe that disease management program would be more cost-effective by decreasing HF readmission rate, Taiwan national health insurance (NHI) launched HF post-acute care program with multi-discipline team approach on July 1, 2017 [34].

This study has several limitations. First, this was a retrospective cohort study performed in a tertiary referral center in Taiwan. The study population comprised patients with LVEF $<40 \%$ at their first hospitalization for HF. Therefore, the results may not be generalizable to the spectrum of HF patients. Second, the patient number was small. Although this study included a control group, larger multicenter studies are needed for a clearer picture of the effectiveness of the HFDMP and a different way to present them. Third, although the HFDMP included psychosocial surveillance, no data were collected for the non-HFDMP group. Further prospective randomized studies are needed to determine the psychosocial effects of the HFDMP. Finally, the patient number differed between the intervention group and the control group. Nevertheless, except for ICD, baseline demographic and clinical characteristics did not significantly differ between the two groups. 


\section{Conclusions}

This study developed and evaluated the effectiveness of an HFDMP in de novo HF patients with LVEF $<40 \%$ over a 1-year follow-up period. Comparisons with the non-HFDMP group showed that the program reduced recurrent events of hospitalization, especially in HF patients with ischemic cardiomyopathy. Further studies are needed to investigate whether the difference resulted from the cardiac rehabilitation and psychosocial intervention received by the HFDMP group.

\section{Abbreviations}

ACEl: Angiotensin converted enzyme inhibitor; AF: Atrial fibrillation; ARB: Angiotensin receptor blocker; AT: Anaerobic threshold; CKD: Chronic kidney disease; CRT: Cardiac resynchronization therapy; HF: Heart failure; HFDMP: Heart failure disease management program; HFrEF: Heart failure with reduced ejection fraction; ICD: Implantable cardioverter defibrillator; ICM: Ischemic cardiomyopathy; LVEF: Left ventricular ejection fraction; MI: Myocardial infarction; PAD: Peripheral artery disease; PCl: Percutaneous coronary intervention; VE: Minute ventilation

\section{Acknowledgements}

I would like to acknowledge Dr. Yu-Tung Huang, PhD, Associate Research Fellow, Center for Big Data Analytics and Statistics, Chang Gung Memorial Hospital, Linkou, for his help in reviewing the results.

\section{Authors' contributions}

SMC led the conception and design of study, and revised the draft of the manuscript. YNF collected the research data and prepared the draft of the manuscript. LYW, MKW, and THY performed clinical works and organized the collected data. PJW, YLC, and CLH performed the statistical analysis and drafted the manuscript. All authors read and approved the final manuscript.

\section{Funding}

We have no support or funding to report.

\section{Availability of data and materials}

The datasets generated and/or analyzed during the current study are available in the repository https://doi.org/10.6084/m9.figshare.9907250.

\section{Ethics approval and consent to participate}

This study was approved by the Human Investigation Committee of the Institutional Review Board (IRB) of Chang-Gung Memorial Hospital; IRB number: 104-5591B, and compliant with the principles set forth by the Declaration of Helsinki Principles. All the data obtained was anonymized. The need for consent was waived by the IRB of our hospital.

\section{Consent for publication}

Not applicable.

\section{Competing interests}

The authors declare that the research was conducted in the absence of any commercial or financial relationships that could be construed as a potential conflict of interests.

\footnotetext{
Author details

${ }^{1}$ Section of Cardiology, Department of Internal Medicine, Kaohsiung Chang Gung Memorial Hospital and Chang Gung University College of Medicine, 123 Tai Pei Road, Niao Sung District, Kaohsiung City 83301, Taiwan, Republic of China. ${ }^{2}$ Heart Failure Center, Kaohsiung Chang Gung Memorial Hospital, 123 Tai Pei Road, Niao Sung District, Kaohsiung City 83301, Taiwan, Republic of China. ${ }^{3}$ Department of Physical Medicine and Rehabilitation, Kaohsiung Chang Gung Memorial Hospital and Chang Gung University College of Medicine, 123 Tai Pei Road, Niao Sung District, Kaohsiung City 83301, Taiwan, Republic of China. ${ }^{4}$ Department of Psychiatry, Kaohsiung Chang Gung Memorial Hospital and Chang Gung University College of Medicine, 123 Tai Pei Road, Niao Sung District, Kaohsiung City 83301, Taiwan, Republic of China.
}

Received: 16 January 2018 Accepted: 30 September 2019

Published online: 15 October 2019

\section{References}

1. Braunwald E. The management of heart failure: the past, the present, and the future. Circ Heart Fail. 2008;1(1):58-62.

2. Chang HY, Wang CC, Wu YW, Chu PH, Wu CC, Hsu CH, Wen MS, Voon WC, Lin WS, Huang JL, et al. One-year outcomes of acute decompensated systolic heart failure in Taiwan: lessons from TSOC-HFrEF registry. Acta Cardiol Sin. 2017;33(2):127-38.

3. Ho YL, Hsu TP, Chen CP, Lee CY, Lin YH, Hsu RB, Wu YW, Chou NK, Lee CM, Wang SS, et al. Improved cost-effectiveness for management of chronic heart failure by combined home-based intervention with clinical nursing specialists. J Formos Med Assoc. 2007;106(4):313-9.

4. Gonseth J, Guallar-Castillon P, Banegas JR, Rodriguez-Artalejo F. The effectiveness of disease management programmes in reducing hospital readmission in older patients with heart failure: a systematic review and meta-analysis of published reports. Eur Heart J. 2004;25(18):1570-95.

5. Ponikowski P, Voors AA, Anker SD, Bueno H, Cleland JG, Coats AJ, Falk V, Gonzalez-Juanatey JR, Harjola VP, Jankowska EA, et al. ESC guidelines for the diagnosis and treatment of acute and chronic heart failure: the task force for the diagnosis and treatment of acute and chronic heart failure of the European Society of Cardiology (ESC). Developed with the special contribution of the heart failure association (HFA) of the ESC. Eur J Heart Fail. 2016;18(8):891-975.

6. Bekelman DB, Plomondon ME, Carey EP, Sullivan MD, Nelson KM, Hattler B, McBryde CF, Lehmann KG, Gianola K, Heidenreich PA, et al. Primary results of the patient-centered disease management (PCDM) for heart failure study: a randomized clinical trial. JAMA Intern Med. 2015;175(5):725-32.

7. Jaarsma T, van der Wal MH, Lesman-Leegte I, Luttik ML, Hogenhuis J, Veeger NJ, Sanderman R, Hoes AW, van Gilst WH, Lok DJ, et al. Effect of moderate or intensive disease management program on outcome in patients with heart failure: coordinating study evaluating outcomes of advising and counseling in heart failure (COACH). Arch Intern Med. 2008; 168(3):316-24

8. Amorim LD, Cai J. Modelling recurrent events: a tutorial for analysis in epidemiology. Int J Epidemiol. 2015;44(1):324-33.

9. Rich MW, Beckham V, Wittenberg C, Leven CL, Freedland KE, Carney RM. A multidisciplinary intervention to prevent the readmission of elderly patients with congestive heart failure. N Engl J Med. 1995;333(18):1190-5.

10. Stewart S, Pearson S, Horowitz JD. Effects of a home-based intervention among patients with congestive heart failure discharged from acute hospital care. Arch Intern Med. 1998;158(10):1067-72.

11. Stewart S, Marley JE, Horowitz JD. Effects of a multidisciplinary, home-based intervention on unplanned readmissions and survival among patients with chronic congestive heart failure: a randomised controlled study. Lancet. 1999;354(9184):1077-83.

12. Jerant AF, Azari R, Nesbitt TS. Reducing the cost of frequent hospital admissions for congestive heart failure: a randomized trial of a home telecare intervention. Med Care. 2001;39(11):1234-45.

13. Doughty RN, Wright SP, Pearl A, Walsh HJ, Muncaster S, Whalley GA Gamble G, Sharpe N. Randomized, controlled trial of integrated heart failure management: the Auckland heart failure management study. Eur Heart J. 2002;23(2):139-46.

14. Kasper EK, Gerstenblith G, Hefter G, Van Anden E, Brinker JA, Thiemann DR, Terrin M, Forman S, Gottlieb SH. A randomized trial of the efficacy of multidisciplinary care in heart failure outpatients at high risk of hospital readmission. J Am Coll Cardiol. 2002;39(3):471-80.

15. Capomolla S, Febo O, Ceresa M, Caporotondi A, Guazzotti G, La Rovere M, Ferrari M, Lenta F, Baldin S, Vaccarini C, et al. Cost/utility ratio in chronic heart failure: comparison between heart failure management program delivered by day-hospital and usual care. J Am Coll Cardiol. 2002;40(7):1259-66.

16. Atienza F, Anguita M, Martinez-Alzamora N, Osca J, Ojeda S, Almenar L, Ridocci F, Valles F, de Velasco JA, Group PS. Multicenter randomized trial of a comprehensive hospital discharge and outpatient heart failure management program. Eur J Heart Fail. 2004;6(5):643-52.

17. Mejhert $M$, Kahan $T$, Persson $H$, Edner M. Limited long term effects of a management programme for heart failure. Heart. 2004;90(9):1010-5.

18. Gaudron P, Eilles C, Kugler I, Ertl G. Progressive left ventricular dysfunction and remodeling after myocardial infarction. Potential mechanisms and early predictors. Circulation. 1993;87(3):755-63. 
19. Pfeffer MA, Braunwald E. Ventricular remodeling after myocardial infarction. Experimental observations and clinical implications. Circulation. 1990;81(4):1161-72.

20. Goldstein S, Sharov VG, Cook JM, Sabbah HN. Ventricular remodeling: insights from pharmacologic interventions with angiotensin-converting enzyme inhibitors. Mol Cell Biochem. 1995;147(1-2):51-5.

21. Kim C, Choi HE, Lim YJ. The effect of cardiac rehabilitation exercise training on cardiopulmonary function in ischemic cardiomyopathy with reduced left ventricular ejection fraction. Ann Rehabil Med. 2016;40(4):647-56.

22. Medicare program; hospital inpatient prospective payment systems for acute care hospitals and the long-term care hospital prospective payment system and Fiscal Year 2014 Rates; quality reporting requirements for specific providers; hospital conditions of participation; payment policies related to patient status. Final rules. Federal Register 2013, 78(160):50495-51040.

23. Tung YC, Chou SH, Liu KL, Hsieh IC, Wu LS, Lin CP, Wen MS, Chu PH. Worse prognosis in heart failure patients with 30-day readmission. Acta Cardiol Sin. 2016;32(6):698-707.

24. Pandey A, Golwala H, Xu H, DeVore AD, Matsouaka R, Pencina M, Kumbhani DJ, Hernandez AF, Bhatt DL, Heidenreich PA, et al. Association of 30-day readmission metric for heart failure under the hospital readmissions reduction program with quality of care and outcomes. JACC Heart failure. 2016;4(12):935-46.

25. Senni M, Gavazzi A, Oliva F, Mortara A, Urso R, Pozzoli M, Metra M, Lucci D, Gonzini L, Cirrincione V, et al. In-hospital and 1-year outcomes of acute heart failure patients according to presentation (de novo vs. worsening) and ejection fraction. Results from IN-HF outcome registry. Int I Cardiol. 2014;173(2):163-9.

26. Salem K, Fallata D, ElSebaie M, Montasser A, ElGedamy K, ElKhateeb O. Congestive heart failure disease management program: 1-year population experience from a tertiary center heart failure registry in Saudi Arabia. J Saudi Heart Assoc. 2017;29(2):90-5.

27. Harjola VP, Follath F, Nieminen MS, Brutsaert D, Dickstein K, Drexler H, Hochadel M, Komajda M, Lopez-Sendon JL, Ponikowski P, et al. Characteristics, outcomes, and predictors of mortality at 3 months and 1 year in patients hospitalized for acute heart failure. Eur J Heart Fail. 2010; 12(3):239-48.

28. Taylor CJ, Ordonez-Mena JM, Roalfe AK, Lay-Flurrie S, Jones NR, Marshall T, Hobbs FDR. Trends in survival after a diagnosis of heart failure in the United Kingdom 2000-2017: population based cohort study. BMJ. 2019;364:1223.

29. Chen SM, Chen MC, Tang WHW. Improving care for patients with heart failure: what can Taiwan accomplish? Acta Cardiol Sin. 2007;23(4):211-24.

30. van der Wal MH, Jaarsma T, Moser DK, Veeger NJ, van Gilst WH, van Veldhuisen DJ. Compliance in heart failure patients: the importance of knowledge and beliefs. Eur Heart J. 2006;27(4):434-40.

31. Fitzgerald AA, Powers JD, Ho PM, Maddox TM, Peterson PN, Allen LA, Masoudi FA, Magid DJ, Havranek EP. Impact of medication nonadherence on hospitalizations and mortality in heart failure. J Card Fail. 2011;17(8):664-9.

32. Tung HH, Chen SC, Yin WH, Cheng CH, Wang TJ, Wu SF. Self care behavior in patients with heart failure in Taiwan. Eur J Cardiovasc Nurs. 2012:11(2):175-82.

33. Chen YH, Ho YL, Huang HC, Wu HW, Lee CY, Hsu TP, Cheng CL, Chen MF. Assessment of the clinical outcomes and cost-effectiveness of the management of systolic heart failure in Chinese patients using a homebased intervention. J Int Med Res. 2010;38(1):242-52.

34. Wu CK, Juang JJ, Chiang JY, Li YH, Tsai CT, Chiang FT. The Taiwan heart registries: its influence on cardiovascular patient care. J Am Coll Cardiol. 2018:71(11):1273-83.

\section{Publisher's Note}

Springer Nature remains neutral with regard to jurisdictional claims in published maps and institutional affiliations.

Ready to submit your research? Choose BMC and benefit from:

- fast, convenient online submission

- thorough peer review by experienced researchers in your field

- rapid publication on acceptance

- support for research data, including large and complex data types

- gold Open Access which fosters wider collaboration and increased citations

- maximum visibility for your research: over $100 \mathrm{M}$ website views per year

At $\mathrm{BMC}$, research is always in progress.

Learn more biomedcentral.com/submissions 